\title{
O TEATRO DE JÖEL POMMERAT A PARTIR DE FRAGMENTOS DE JE TREMBLE - ENTRE O DRAMATURGO E O ENCENADOR
}

\author{
Camila Bauer Bronstrup \\ Encenadora e professora de teoria teatral e dramaturgia no Departamento de Arte Dramática \\ (UFRGS) \\ E-mail: camilabauer@yahoo.com.br
}

Este trabalho se propõe a analisar alguns elementos marcantes na poética de Jöel Pommerat, pensando seu lugar no teatro contemporâneo a partir da denominação que ele próprio utiliza para definir seu trabalho enquanto criador: a de "autor de teatro". Para pensar algumas questões relativas aos cruzamentos entre a dramaturgia e a encenação na obra de Pommerat, utilizaremos como exemplo fragmentos de sua peça Je Tremble (Estremeço), encenada em 2008.

Palavras-chave

Jöel Pommerat; Estremeço; dramaturgia contemporânea; autor de espetáculos.
This article aims to analyze some important elements in the poetics of Jöel Pommerat, think-ing about his place in contemporary theater from the name that himself uses to define his work as a creator: "author of theater". To raise some questions about the relation between drama and performance in Pommerat's plays, we will use as example some fragments of his text Je Tremble, staged in 2008.

Keywords

Jöel Pommerat; Je Tremble; contemporary drama; author of performances. 
“Na encenação

eu sou autor, na escritura das palavras, eu sou autor, na pesquisa e concepção eu sou autor. Eu sou, portanto, autor de teatro" (Pommerat apud Cousin, 2015, p. 46). 1

Jöel Pommerat é um dramaturgo e encenador francês de grande destaque na atualidade. Suas obras chamam a atenção da crítica e do público devido ao alto nível de problematização estética, à aguçada sensibilidade das formas e conteúdos abordados, à precisão cênica, à criatividade presente em sua dramaturgia e encenação, além da potência e impacto das imagens produzidas em seus espetáculos, frequentemente considerados "estranhos".

Em tempos de discussões acerca do lugar do drama no teatro contemporâneo, Pommerat é alguém que definiu claramente seu foco de interesse e concepção artística. Ele escreve a dramaturgia de seus próprios espetáculos e prefere se denominar "autor de teatro". Patrice Pavis define suas criações como "encenação de autor", em uma analogia ao "cinema de autor". Para ele, analisando a obra Les Marchands:

A "encenação de autor" encoraja que se trabalhe paralelamente a "trilha sonora", e a "filmagem" das imagens, para em seguida confrontar os dois. Neste contexto, a ligação entre som e imagem é muito instável. $O$ espectador é forçado a mudar constantemente o sentido do movimento de um verso a outro. Ora é o som que precede a imagem, que ilustra, sóbria ou parodicamente, o texto dito. Ora é a imagem que vem primeiro, e se nos impõe como aquilo em que nos faz crer, por contraste com aquilo que diz o texto e, assim, passa a ser então uma mentira. (Pavis, 2010, p. 350).
Nos mais de 30 anos dedicados à escrita, Pommerat consumou sua forma de criação na qual os atores tem um papel importante, mesmo que não auxiliem diretamente na dramaturgia e não a improvisem em cena. Como esclarece, no início do processo de ensaios o texto não está acabado, vai se construindo aos poucos, ainda que solicite aos atores que entrem em cena apenas quando tiverem memorizado o fragmento recebido antes do ensaio. "Eu preciso que eles se apropriem do texto, que estejam com as palavras e não na recitação ou restituição do texto" (Galea e Pommerat, 2005, p. 59), afirma Jöel em sua entrevista a Claudine Galea. Em 1990, movido pelo interesse em aprofundar a pesquisa cênico-dramatúrgica que vinha desenvolvendo, fundou a Companhia Louis-Brouillard, com quem decidiu montar uma peça por ano, ao longo de 40 anos. É uma espécie de plano artístico e ao mesmo tempo uma carta de intenções de trabalhar com as mesmas pessoas para que a linguagem adquirida não se perca e possa ser ampliada.

Pommerat está em pleno vapor criativo e sua produção não cansa de se reinventar. Nos últimos anos, teceu uma variedade considerável de abordagens relacionadas ao drama, indo desde estruturas bastante tradicionais, até procedimentos radicais como a utilização de uma única voz em off que narra toda a peça, com pequenas intervenções sonoras ao vivo, como em Les Marchands, que juntamente com Au Monde e D'une seule main formam sua trilogia sobre o trabalho, a guerra, a fabricação de armas e a morte lenta. Aventurou-se também na criação de fragmentos escritos a partir de relatos e com uma abordagem processual que lembra a do teatro documental, como ocorre em Cet Enfant. Produziu ainda as releituras de estórias para crianças como

\footnotetext{
${ }^{1}$ A As traduções do francês são nossas para fins de pesquisa.
} 
Pinocchio, Petit Chaperon Rouge e, a mais recente, Cendrillon, que são pensadas numa confluência entre os mitos trazidos pelo universo dos contos infantis e a realidade do mundo contemporâneo, fazendo uma crítica audaz às relações familiares na sociedade atual, especialmente entre pais e filhos. Possui, ao todo, cerca de 30 obras, entre suas montagens e publicações. ${ }^{2}$

\section{são todas as contradições que o real não pode abrigar porque a vida em sociedade não lhe permite, essas contradições que existem, mas das quais desviamos. E aqui, não desviamos." (Pommerat, em Galea e Pommerat, 2005, p. 60)}

Para esta análise, iremos nos concentrar na obra Je Tremble (1) et (2), criada em 2007 e 2008, durante o período em que Pommerat esteve como artista residente no Bouffes $d u$ Nord, a convite de Peter Brook. Esta peça foi composta em duas etapas, devido ao interesse do grupo de aprofundar questões trazidas em Je Tremble (1). O texto é formado por diversos quadros que, aos poucos, cruzam-se através da memória do Apresentador, que tenta desde o início estabelecer uma relação de unidade e interdependência com o espectador: "Senhoras e senhores, nós estamos juntos na verdade desde sempre e pra sempre. Sim, nós estamos juntos desde sempre, sem termos escolhido, e sim, porque é assim", afirma ele na terceira cena da peça. Na descrição inicial do texto, lido às vezes como um show de cabaret ou um espetáculo de variedades, a ação se desenvolve no seguinte espaço:

\begin{abstract}
Em algum lugar que poderia ser chamado de cabaret ou teatro, onde o sério e o leve, o grave e o louco por uma noite não se oporiam mais, alguns exemplares da humanidade vem contar ou procurar uma verdade, sob a condução de um apresentador um pouco desconcertante.

Não tendo nenhum outro estímulo a não ser o de fazer espetáculos de tudo e de escapar ao limite entre o bom e o mau gosto, o verdadeiro e o falso, este lugar poderia ser um espelho, este mesmo espelho dos contos no qual viemos nos interrogar ou desvendar. ${ }^{3}$
\end{abstract}

O teatro de Jöel Pommerat constrói espaços onde "tudo é possível", onde o monstruoso e o abismal da vida quotidiana são revelados e denunciados poética e esteticamente. $O$ dramaturgo se pergunta o que pode nos fazer estremecer realmente, hoje em dia, já que tudo é tão banalizado? Para ele, o construído em cena deve perturbá-lo, surpreendê-lo, como quer que aconteça ao espectador. Quando isso não ocorre, o público se torna passivo, e o que ele busca é o seu desconcerto, seu estado ativo, no qual é necessário desfazer e refazer constantemente seu sistema de referências. Em Je tremble, este desconcerto se produz ao trazer à tona questões existenciais e colocar em tensão nosso próprio sentido de existência:

\footnotetext{
O APRESENTADOR

Senhoras e senhores, a minha pergunta irá surpreendê-los talvez... tem alguém, nesta sala, esta noite, que não existe?

Minha pergunta parece estúpida? Vocês acham por acaso que eu sou um
}

\footnotetext{
${ }^{2}$ Apesar do amplo reconhecimento internacional, no Brasil seu trabalho como encenador segue inédito e sua obra dramatúrgica nunca foi publicada, ainda que dois textos seus tenham sido traduzidos e levados ao palco em 2012: Cet Enfant (Esta Criança), que recebeu montagem da Companhia Brasileira, com direção de Márcio Abreu, e Je Tremble (Estremeço), encenada pela Companhia Stravaganza, com direção de Camila Bauer.

3 Todas as traduções citadas de Je Tremble foram feitas por Giovana Soar para a montagem de Estremeço, realizada em Porto Alegre.
} 
pouco louco -

Mas vocês sabem, nós podemos viver perfeitamente sem existir.

(...) Eu mesmo conheci um homem, que era um amigo, com quem isso aconteceu...

Ah, sim, claro, ele existia um pouco. Do lado de fora, em todo caso, para os outros. E quando vinha na minha casa, eu o via claro, como eu e vocês, eu o via sentar-se na minha poltrona, na minha frente.

Atrás do apresentador uma cadeira vazia aparece. Ele se volta. Ele olha a cadeira e se aproxima dela.

Mas ele, diferentemente de mim, ele não SENTIA que ele existia,

Ele não tinha o SENTIMENTO da sua existência

e era terrível vejam bem, terrível para ele.

Este homem sofria muito, e ele estava inconsolável.

A cadeira desaparece.

O Apresentador volta-se para o público. Um dia, a vida havia lhe tirado a impressão de existir e tinha lhe dado a impressão de não existir.

Um dia a vida lhe deu um vazio no lugar de alguma coisa.

Para construir este tipo de abordagem que destaca princípios de incerteza, de questionamento, de problematizações do eu frente ao real, Pommerat escreve textos que dialogam com questões humanas de ordem marcadamente existencialista. É forte sua identificação com os escritos do filósofo François Flahault, autor da obra Le Sentiment d'exister (2002), cujas ideias permeiam as falas de Je Tremble. Nesta cena, repleta de indicações cênicas, ${ }^{4}$ a própria presença humana é posta em relevo por meio de um personagem que aparece e desaparece. Esta opção por compor uma dra- maturgia rica em didascálias manifesta um desejo de precisar em palavras seu olhar imagético de dramaturgo-encenador, funcionando como um intento de comunicação com o leitor do texto, de modo autônomo ao espetáculo. Afirma Pavis (2010, p. 347) acerca de Pommerat:

\begin{abstract}
Autor e encenador de suas próprias peças, faz bem mais do que acampar as funções e poderes; inventa um método de trabalho e de intervenção que o coloca no centro de uma saia justa permanente entre texto e imagem, um centro que em seguida se transforma no lugar e no momento em que o espectador deve, ele próprio, situar-se, um centro chamado silêncio.
\end{abstract}

O mesmo ocorre com alguns mecanismos narrativos presentes em sua obra, tais como os procedimentos cinematográficos que utiliza de recorte, montagem, as sugestões de trilha sonora e de luz, os elementos de cenografia, de figurino, entre outros signos cênicos que já aparecem de modo alusivo no texto dramático.

Propostas deste tipo desafiam o encenador contemporâneo, já que suas encenações contam com efeitos significativos de luz e som, que potencializam ferozmente o texto escrito, ${ }^{5}$ como ocorre no fragmento a seguir, de Je Tremble, onde dois personagens estão em cena, mas apenas um fala, o outro emite seu discurso somente por meio da voz em off, gerando uma tensão de opostos:

\section{A MULHER MUITO VELHA \\ Eu vou deixar você. \\ Nós vamos nos separar. \\ Eu decidi não ser racional hoje.}

\footnotetext{
4 Inicialmente é a cadeira que aparece e desaparece, depois um homem vestido surge e desaparece, seguido do mesmo homem nu, e por fim ele volta vestido.

5 Neste sentido, a maestria da composição cênica de Pommerat pode, às vezes, desencorajar os encenadores a buscarem seus textos como material de criação. Como afirmam Boudier e Pisani "para alem de uma regra infeliz e não escrita do teatro contemporâneo que deseja que não se montem as peças dos autores que criam suas próprias obras, os textos de Pommerat, extremamente interessantes, seguem à espera do criador que deseje lhes devolver à vida" (2008, p. 157).
} 
Então nós vamos parar

parar de nos ver.

Você não me ama como eu preciso que você me ame

você não me ama como eu gostaria que você me amasse

você me ama por aquilo que eu não sou.

\section{VOZ DO APRESENTADOR}

Meu corpo não se mexia mais e se contentava apenas em olhar para ela.

Como podíamos ter chegado neste ponto?

O que aconteceu que eu não havia percebido?

Escuro.

Luz. A Mulher muito velha está sentada na poltrona. O Apresentador entra, vai até ela. Ele olha para ela. Acaricia seus cabelos depois vai embora. Quando ele sai de cena, a mulher muito velha se transforma em uma jovem mulher. Quando ele entra em cena, a jovem volta a ser velha. Quando ele deixa a cena novamente, o fenômeno se reproduz.

A poética de Pommerat brinca com o real e com nossa percepção acerca do que seja o real, utilizando-se de jogos de luz e escuridão, de vazios e preenchimentos. Suas construções se acercam àquelas envolvendo um "modelo cinematográfico" o qual, como aponta Pignon (2015, p. 87), é "sobretudo um efeito de percepção", "que suscita no espectador uma fascinação perturbadora entre o impulso de reconhecimento e a sensação de estranhamento". No fragmento acima citado, somos levados a pensar nosso olhar sobre a vida e sobre nós mesmos, sobre conceitos como belo, feio, jovem, velho, realidade, imaginário, distorção e percepção. Para Pavis (2010, p. 350) “A arte consiste em desestabilizar o espectador: ele deve ir da palavra para a imagem ou o contrário? No caso de Pommerat, essa hesitação provém da pequena defasagem entre o visto e o ouvido, ali onde se coloca a ironia".
"Só temos tempo

de captar um pouco do real quando o fabricamos poeticamente" (Pommerat, em Galea e Pommerat, 2005, p. 59)

Em seu Théâtre en présence (2007, p. 26), Jöel afirma que "O teatro não serve a nenhuma causa, ao contrário, para mim, ele deve contaminar a reflexão e tentar nos fazer sair de nós mesmos. Neste caso, talvez, ele seja político". Para isso, busca formas que levem o espectador a uma reflexão sobre sua própria existência. Pensando com Hegel e Sarrazac que "a forma é um reservatório do conteúdo e as formas antigas deixam transpirar as velhas ideologias (...) Escrever no presente não é contentar-se em registrar as mudanças da nossa sociedade; é intervir na 'conversão' das formas" (Sarrazac, 2002, p. 33-34). Neste sentido, suas obras possuem formas que nos permitem observar com clareza a contaminação do dramático pelo épico e a busca por múltiplos mecanismos de enunciação que nos façam refletir sobre diferentes questões humanas. Tomando como exemplo a fala inicial de Je Tremble, temos a ação enunciada por meio de uma narrativa que antecipa os acontecimentos do espetáculo:

\section{O APRESENTADOR}

Senhoras e senhores, boa noite.

Antes de iniciar este espetáculo eu gostaria de lhes dizer uma coisa uma coisa

que vocês vão ver

é um pouco particular.

Estamos aqui no início do nosso espetáculo, intitulado "Estremeço",

espetáculo durante o qual será bem pouco provável que vocês sejam levados a estremecer realmente este título sendo apenas um título meio... sei lá -

quase que um título por acaso.

Mas ao mesmo tempo, existe uma coisa que acontecerá com certeza e isto eu tenho o dever de lhes contar, 
senhoras e senhores, eu tenho o dever de lhes contar.

No final deste espetáculo, no último instante deste espetáculo, no último minuto

(silêncio)

eu morrerei.

Eu vou morrer

Sim.

Podemos notar neste fragmento outra fonte bastante utilizada por Jöel Pommerat: o metateatro. Em muitas de suas obras os mecanismos da representação não são apenas revelados aos espectadores, mas acabam também se tornando foco de uma importante reflexão formal. O autor ironiza o próprio título da peça e tenta acabar com qualquer expectativa que o leitor/espectador possa ter quanto a se emocionar com o espetáculo. Recursos deste tipo, bem como os dispositivos épicos de narração e distanciamento, são frequentes em sua obra, conforme podemos observar no trecho acima, quando o Apresentador anuncia sua morte que, segundo ele, irá ocorrer ao final do espetáculo. Este fato se construirá ao longo de toda a peça, por meio de ações dramáticas. Assim, logo na primeira cena, Pommerat nos apresenta a problemática consequência/ causa, bastante comum no teatro contemporâneo - especialmente em obras de construção fragmentária - que acaba por questionar a tradicional estrutura de causa e consequência presente em formas mais tradicionais. Aqui, sabemos que ele irá morrer e que isto talvez não nos faça estremecer. Resta-nos agora descobrir como e porquê.

Por meio dessa linguagem, Pommerat constrói uma forma anti-realista, ainda que busque constantemente o real. Em Je Tremble, temos uma cena na qual a Sereia conversa com seu amante/marido, que deseja a amputação de sua cauda, mesmo que para isso ela perca a voz. A dramaturgia traz à superfície texturas humanas complexas e dicotômicas, reais, ainda que se utilize de personagens fantásticos como a Sereia, o Homem Vampiro e suas muIheres, ou o Homem que não existia.

O teatro é a minha possibilidade de captar o real e de conduzir o real a um alto nível de intensidade, de força. (...) É por isso que a arte é essencial para mim. Com meios que são artifícios, eu busco o real. Não a verdade. Só me interessa a realidade. Dizem que minhas peças são estranhas. Mas eu passo meu tempo procurando o real (Pommerat, em Galea e Pommerat, 2005, p. 59).

Assim, investe em uma construção narrativa que mescla imagens figurativas a outros enunciadores ficcionais capazes de produzir um efeito de real, sem abrir mão dos mundos possíveis denotados em cena, de modo a oferecer ao espectador lugares onde tudo se passa como num sonho, brincando com o imaginário que compõe o mundo de referências do receptor: sereia, vampiro, fada, lobo mau, o palhaço branco, a terrorista, o presidente, o policial, o homem mais rico do mundo. Neste sentido, ao mesmo tempo em que trabalha com fábula, personagem, ação e conflito (elementos tradicionais do drama), a forma que Jöel encontra para compor essa estrutura é por meio do isolamento dos personagens, do vazio, da fragmentação e da construção diegética de universos autônomos. Pommerat afirma:

Eu queria realizar um espetáculo que rompesse com a forma narrativa magistral, sair das grandes histórias, porque neste sistema sempre há um momento onde temos que ligar um ponto A a um ponto B. Os dois pontos são interessantes, mas a passagem entre eles não tem nada de essencial. O que 
é apaixonante no trabalho com fragmentos independentes é que estamos livres desta obrigação. Só conservas aquilo que te parece indispensável. (Pommerat apud Martinez, 2015, p. 94)

O que lhe interessa é o ponto forte da ação, os fragmentos que portam em si um clímax, ainda que a totalidade da obra possa parecer linear. Na composição por fragmentos, não há o desenvolvimento de uma ação dramática dominante, causal, no sentido aristotélico, mas a apresentação de situações e estruturas capazes de evocar imagens fortes e criar ações verbais geradoras de tensões dramáticas. Neste sentido, não podemos falar de uma evolução dramática, mas da sucessão de situações e discursos potentes, de micronarrativas que formam o todo da enunciação. Este tipo de estrutura, segundo Vinaver em seu Écrits sur le théâtre 2 (1998, p. 190 apud Sarrazac, 2011 , p. 46), retrata "uma espécie de olhar angustiado sobre a realidade, porque não podemos apreendê-la senão de modo parcial. Já não vemos a realidade, vemos realidades". 0 formalista russo Tomachevsky, define fábula como o "conjunto de elementos ligados entre si que nos são comunicados ao longo da obra" que "representa a passagem de uma situação a outra" (apud Sarrazac, 2011, p. 47). São justamente esses pontos de passagem que perderam o interesse para Pommerat.

Se pensarmos com Sarrazac (2011, p. 39) que a função do desenlace era uma "espécie de triunfo da cronologia que é também uma bio-lógica", o que Pommerat faz é construir a obra com base em diferentes pontos centrais, aquilo que é realmente fundamental, mas não de uma história unívoca, e sim de diferentes recortes. Os personagens surgem em cena no ápice de suas crises, trazendo à tona conflitos que ecoam no vazio. Assim, o final da obra é o desfecho de um pedaço de história, conectada a outras por fios mais ou menos sutis, que podem possuir diferentes naturezas conectivas, como o topic narrative, a isotopia, a estrutura-temática, actancial, entre múltiplas abordagens e problematizações.

Nesta construção, Jöel parte da ideia de uma caixa escura, na qual as coisas (imagens/ palavras/personagens/situações) emergem, ganham vida, para depois sucumbirem e tudo se tornar escuridão outra vez. Segundo Pommerat, este ponto negro é fundamental para limparmos nosso olhar e nossa percepção da poluição da vida, aguçando nossos sentidos para imagens que muitas vezes se parecem mais a alucinações do que a realidades. $E$ isso está marcado na estrutura dramatúrgica, grifado em seus vazios e escuros.

"Galea - Terias escrito escrito sem a cena? Pommerat - Acho que não. Só o teatro permite estar na encarnação, ao mesmo tempo no corpo da presença e das palavras." (Pommerat, em Galea e Pommerat, 2005, p. 56)

Os personagens, para o dramaturgo, são inicialmente criações artificiais, que encarnam ideias e pontos de vista trazidos pelo autor; são abstrações, como ele mesmo define (apud Martinez, 2015, p. 96), que adquirem singularidade aos poucos, no contato com outros elementos e com o trabalho do ator. Pommerat investe também em contornos que funcionam como representações sociais e estados emocionais: mãe, pai, irmão, irmã, mulher jovem, mulher que está muito mal, mulher muito grávida, prostituta, mulher testemunha, a procuradora, um senhor, o adolescente, etc. Estas figuras transitam entre o dramático e o 
narrativo, aproximando-se da arte do rapsodo teorizada por Sarrazac (2011), na medida em que mesclam relato direto e imitação. Em obras como Je Tremble, os personagens oscilam entre sujeitos (observadores do mundo/vida) e objetos (observados pelo público, no cabaret). Existe uma mistura de linguagens - lírico, épico e dramático - a fim de captar o homem contemporâneo, buscando formas de contemplar suas problemáticas e inquietações. Se tomarmos como exemplo o personagem da Mulher de Camiseta, vemos que ela narra o que aconteceu com sua mãe, ao mesmo tempo em que sofre as consequências do passado descrito e ainda não superado. É um discurso forte, político, que marca a situação da classe operária na França de finais dos anos 60:

\section{A MULHER DE CAMISETA}

Toda a força que ela colocava neste trabalho ela tirava do resto da sua vida. Eu era criança, ela começava a não me enxergar mais

a mim também.

Ela queria tanto vencer.

Um dia, entre a lâmina e a madeira minha mãe deixou um dos seus dedos da mão direita.

Impossível compreender o que ela não tinha feito direito neste dia

Seu dedo era agora como um objeto, uma parte dela que tinha perdido a vida, então, ela o jogou fora.

Ela teve que ficar de licença por três meses.

Depois, ela pediu de volta o mesmo posto

(...)

Minha mãe sofria mas ela não se lamentava por estar lá.

Algumas semanas depois de ter voltado para a fábrica, ela cortou acidentalmente um outro dedo.

Desta vez o sofrimento a deixou quase louca.

(...)

Suas mãos começavam a parecer duas pinças.

Mas, depois dos três meses de licença obrigatória, ela voltou e lutou para re- cuperar o seu posto.

Eu acho que nesta época eu realmente não existia mais.

Nestes casos, o uso da narrativa e dos monólogos é fundamental como ferramenta de isolamento e solidão da personagem. Alfred Döblin aponta o enfraquecimento do diálogo ao afirmar que "é igualmente um dogma, mas um dogma que se desfaz em ruínas, pensar [...] o desenvolvimento do drama unicamente numa ação dialogada" (Alfred Döblin, apud Sarrazac, 2002, p. 133). Em peças como esta podemos observar diversos momentos nos quais se confirma que "privado da sua função tradicional de formular o conflito e de o conduzir ao seu termo, através de uma série finita de relações duais, o diálogo dramático desaparece progressivamente e enfraquece, tal como um órgão que deixou de ter utilidade" (Sarrazac, 2002, p. 138). Em Je Tremble, são poucos os momentos de diálogo; com frequência o enunciado se endereça diretamente ao espectador, interlocutor quase actancial do discurso. As vozes que falam e anunciam que "nós não temos mais futuro" ou que "as coisas não estão bem", precedidas ou seguidas de um clássico "senhoras e senhores", compõem o coro que também pergunta se "tem alguém aqui, esta noite, que não existe". Relativiza-se assim a síntese homem-personagem que se desenvolvia no palco por meio do diálogo.

Deste modo, a questão do endereçamento se revela importante em sua obra: com quem o sujeito fala? Esta pessoa lhe escuta? Os actantes são prisioneiros de suas próprias dúvidas, sonhos, queixas, frustrações, esperanças e desilusões, vítimas de suas próprias ideologias e lutas. Em muitos monólogos do drama moderno e contemporâneo, os personagens rememoram e contam fragmentos de suas 
vidas ao invés de agir. "A personagem tornase testemunha da sua própria existência e da sua época", aponta Sarrazac (2002, p. 161).

Nesta aproximação entre personagem, ação e vida real, Pommerat opta por uma linguagem verbal simples, ao mesmo tempo em que produtora de significações complexas, especialmente pela teia de discursos que compõem esse mosaico de situações presente em sua obra. Em algumas peças não há desenvolvimento e finalização de uma trama, mas a apresentação de situações com conflitos sem solução. Não encontramos o desenrolar de linhas principal e secundária de ação, mas a justaposição desierarquizada de fragmentos de humanidade. Nos é apresentada uma visão prismática e documental acerca da própria existência humana, atuando como registro ficcional de uma realidade difusa e não mais capturável de modo orgânico, centralizado e homogêneo, como destaca o próprio dramaturgo. Assim, "o mundo é muito mais uma epopeia com múltiplos episódios do que um drama onde a unidade de ação se manifestaria" (James, William apud Sarrazac, 2002, p. 230). Jöel abre mão da unidade e valoriza a multiplicidade de ações que nos apresenta diferentes pontos de vista sobre um mesmo tema, descentralizando o discurso.

"Minha busca não é só artística, mas humana, pessoal, reflexiva" (Pommerat, em Galea e Pommerat, 2005,

Pommerat busca construir lugares que nos permitam pensar, contemplar o monstruoso: aquilo que preferiríamos não ver, mas que vamos ver assim mesmo, como nas "cabines de curiosidades" que pegam emprestadas fontes do circo, da televisão, dos truques de mágica, do music-hall, etc. Esta diversidade caracteriza o seu teatro, que investe em um existencialismo revelador de patologias sociais: depressão, jogo de aparências, poder, capitalismo, queda da unidade familiar, manipulação, busca exacerbada pela felicidade, etc.

Para o encenador, o principal procedimento receptivo é a observação, que vem por meio do "mostrar" que se desenvolve em cena, não de um demonstrar como ocorre num teatro de tese política. "É este nosso trabalho no teatro: mostrar, o que mostrar, como mostrar. E sem excluir o texto, porque a palavra também deve ser mostrada" (Pommerat, 2007, p. 26). O autor se utiliza da justaposição de diferentes pontos de vista como mecanismo dramatúrgico, a fim de que o espectador possa compor sua própria análise a partir das problematizações trazidas pela obra. Busca construir peças com códigos múltiplos, que demandem uma implicação expectatorial frente a estrutura proposta. O teatro é pensado por ele como um "lugar possível de interrogação e de experiência do humano, não um lugar onde vamos procurar a confirmação daquilo que já sabemos, mas um lugar de possíveis e de retomadas em questão daquilo que nos parece adquirido" (Pommerat apud Pavis, 2010, p. 352).

Estamos, portanto, diante de um dramaturgo que transita entre diferentes mecanismos dramáticos e construtores cênicos. Seu olhar enquanto encenador impregna sua dramaturgia de contrastes, ruídos, ironias, dissonâncias, contradições, silêncios, escuros, vazios, imagens, sonoridades, recortes, enquadramentos, entre muitos outros elementos que poucas vezes são encontrados na dramaturgia produzida por dramaturgos que estão distanciados da prática cênica. Neste 
sentido, dramaturgos-encenadores como Jöel Pommerat, mas também poderíamos citar Sarah Kane, Jean-Luc Lagarce, Michel Vinaver, Valère Novarina, Ivan Viripaev, Jan Lawers, e a lista é imensa, parecem haver superado esta querela entre texto e encenação, nos mostrando o quanto uma dramaturgia dita de "gabinete" pode ser tratada em um contexto atual no seio da criação e da prática artística, em uma confluência entre dramaturgia pensada enquanto texto escrito, como manifestação monossemiótica (posto que se utiliza "apenas" das palavras como expressão), e a polissemia da encenação contemporânea que Pommerat já prevê em gérmen e potencialidades quando escreve solitário seu texto dramático.

Referências

BOUDIER, Marion e PISANI, Guillermo. Jöel Pommerat: une démarche qui fait oeuvre. Jeu: revue de théâtre. Número 127 (2), 2008, p.150-157. Disponível em <http://www.erudit. org/culture/jeu1060667/jeu1114969/23855ac. html?vue=resume $>$. Consultado em 07 de novembro de 2015.

COUSIN, Marion. L'auteur en scène: pour une redéfinition des relations entre le texte et la scène. Revue d'Études Théâtrales. Écrire pour le théâtre aujourd'hui. Modèles de représentation et modèles de l'art. Paris: Presses Sorbonne Nouvelle, Registres Hors Série 4, 2015.

GALEA, Claudine e POMMERAT, Jöel. Dialogue entre Claudine Galea et Jöel Pommerat, novembre-décembre 2005. Disponível em <http://www.carrefourtheatre.qc.ca/media/ Pommerat_Ubu\%20Scenes_Europe.pdf $>$.
Consultado em 4 de novembro de 2015.

MARTINEZ, Ariane. Dramaturgie du miroitement. Le modèle du spectacle de variété chez Jöel Pommerat. Revue d'Études Théâtrales. Écrire pour le théâtre aujourd'hui. Modèles de représentation et modèles de l'art. Paris: Presses Sorbonne Nouvelle, Registres Hors Série 4, 2015.

PAVIS, Patrice. A Encenação Contemporânea: origens, tendências, perspectivas. São Paulo: Perspectiva, 2010.

PIGNON, Rafaëlle Jolivet. L'écriture scénique de Jöel Pommerat à l'épreuve du modèle cinématographique. Revue d'Études Théâtrales. Écrire pour le théâtre aujourd'hui. Modèles de représentation et modèles de l'art. Paris: Presses Sorbonne Nouvelle, Registres Hors Série 4, 2015.

POMMERAT, Jöel. Je Tremble (1) et (2). Paris: Actes Sud, 2009.

. Théâtre en présence. Paris: Actes Sud, 2007.

SARRAZAC, Jean-Pierre. Juegos de sueño y otros rodeos: alternativas a la fábula en la dramaturgia. México D.F.: Toma, Paso de Gato, 2011.

. O Futuro do Drama. Porto: Campo das Letras, 2002.

Recebido em 13/12/2015. Aprovado em 12/06/2016. 